\title{
Research Paper: Socioeconomic Determinants of Sustainability of Agricultural Production in Rural Areas: A Case Study in Golestan Province
}

\author{
Mohammad Sharif Sharifzadeh ${ }^{1 *}$, Gholamhossein Abdollahzadeh ${ }^{1}$
}

1. Associate Professor, Department of Agricultural Extension and Education, Faculty of Agricultural Management, Gorgan University of Agricultural Sciences and Natural Resources, Gorgan, Iran

Citation: Sharifzadeh, M. Sh., \& Abdollahzadeh, Gh. (2017). Socioeconomic Determinants of Sustainability of Agricultural Production in Rural Areas: A Case Study in Golestan Province. Journal of Sustainable Rural Development, 1(2), 121-136. https://doi.org/10.29252/jsrd.01.02.121

doi: $:$ https://doi.org/10.29252/jsrd.01.02.121

Article info:

Received: 25 Mar. 2017

Accepted: 10 Sep. 2017

Keywords:

Sustainable agriculture, Wheat cropping systems, Sustainability, Sustainability determinants, Socioeconomic factors

\section{ABSTRACT}

Purpose: Sustainability of agricultural production systems is an important issue, particularly in countries which heavily rely on this economic sector. Different methods have been proposed to assess sustainability of such systems from various viewpoints. Nonetheless, limited attention has been paid to find key factors in agricultural sustainability. While researchers often recognize ecological factors as the main element affecting sustainability, other factors play an important role in the sustainability of a farming system, too. This study proposes a method to analyze the determinants of sustainable crop production, and applies it to wheat cultivation in Golestan Province, Iran.

Methods: We used a survey instrument to gather data from 234 farmers in this area. To measure sustainability of wheat cropping systems as the dependent variable, a composite index was established based on 13 individual related indicators using principal component analysis method.

Results: The results of path analysis revealed that "technical knowledge" (with path coefficient of 0.806 ) has the highest impact on sustainability. Other variables of "technology usage" $(0.165)$ "farm income" (0.020), "accessibility on agricultural extension and education services" $(0.561)$, "accessibility on agricultural supportive services" $(0.021)$, "satisfaction of farming job" $(0.321)$, and "social participation in rural affairs" (0.047) positively and "land fragmentation" (-0.313) negatively influenced the sustainability of wheat cropping system.

Conclusion: Recommendations are provided for future policy makings to improve sustainability processes in farming systems.

\section{Introduction}

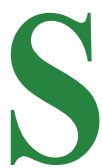

ustainability is a conflicting concept, with no univocal definition (De Luca et al., 2017). Many authors agree on defining sustainability science as a multidisciplinary, interdisciplinary, problem-driven field that addresses essential questions on the interactions between nature and society (Carpenter et al., 2009; Levin \& Clark, 2010; Miller, 2014). Given the importance of agriculture as the crucial

* Corresponding Author:

Mohammad Sharif Sharifzadeh, PhD

Address: Department of Agricultural Extension and Education, Faculty of Agricultural Management, Gorgan University of Agricultural Sciences and Natural Resources, Gorgan, Iran.

Tel: +98 (17) 32457062

E-mail: sharifsharifzadeh@gamil.com 
provider of food, fiber, fuel and shelter for humans, sustainable development of this sector is of utmost importance (Pashaei Kamali, Borges, Meuwissen, de Boer, \& Oude Lansink, 2017).

Hansen and Jones (1996) defined sustainable agriculture as "the ability of cropping systems to continue into the future." In other words, sustainable agriculture means "preservation of the adaptive capacity of cropping systems" (Park \& Seaton, 1996). Sustainability keeps the ability to farm and produce food into the future, without reducing the options for future generations. We agree with three main perceptions of sustainability identified by Yunlong and Smit (1994). The first is the ecological definition of sustainability, which focuses on biophysical processes and continued productivity of performance ecosystems. The second is the economic definition of sustainability, which is principally concerned with the long-term preservation of the benefits of farming to agricultural producers. The third is the social definition, which addresses the continued satisfaction of vital human needs for food and shelter, as well as equity, education, security, freedom, employment and recreation (De Luca et al., 2017).

Production systems are now viewed as complex integrated farming systems involving economic, environmental, and social factors (Edwards et al., 1990; Charles, \& Youngberg 1990). Cropping systems identified by characteristics such as on-farm inputs, diversity of products, restricted marketing, and Integrated Pest Management (IPM) that have emerged among the mainstream agricultural industry (Harwood, 1993; Madden \& Chaplowe, 19995). Extensive efforts to create and disseminate sound and practical information about sustainable farming systems have accompanied with the rising interest in the assessment criteria for sustainable agriculture, development of indices to measure sustainability in farm operations, and explain factors contributing to sustainability (Smolik, Dobbs, \& Rickerl, 1995; Alonge \& Martin, 1995; Ikerd, 1996; Ikerd, Devino, \& Traiyongwanich 1996; Roberts \& Swinton, 1996).

Alternative approaches for evaluating sustainability have been created and used according to what is to be sustained. Rather than becoming involved in the question of how to measure sustainability, this paper investigate a more practical issue of what determines sustainable cropping system. Sustainability is the result of several processes (social, cultural, economic, physical, and ecological processes) working either together or independently (Clark \& Dickson, 2003). Also agricultural sustainability is not only significantly affected by the ecological factors, but is also impacted directly by changes in socioeconomic factors at both farm and nonfarm scale (Tilman, Cassman, Matson, Naylor, \& Polasky 2002). The social and economic determinants of farming system sustainability are also significant in many developing countries, because agriculture is the major source of livelihood support in these countries (Rao \& Rogers, 2006).

In Iran, during the 1990s, the farming sector has experienced intense debate over the orientations of sustainable farming systems. This resulted in a general consensus among agricultural development practitioners that goals should include increasing production (for an ever increasing population), preventing soil erosion, reducing pesticide and fertilizers contamination, protecting biodiversity, preserving natural resources, and improving farmers' well-being (Rezaei-Moghadam, Karami, \& Gibson, 2005). Currently one of the major objectives of Iran Ministry of Agri-Jihad is to have a sustainable and efficient farming sector, which uses safe and environmental-friendly production methods and provides quality products that meet consumers' demands (Ministry of Agriculture, 2005).

A growing consensus believes that long-term sustainability of agriculture and production systems can be enhanced through locally-based planning and management at the farm scale. Therefore, within farming systems analysis, many argue that some forms of agricultural management are more sustainable than others (Dalsgaard, Lightfoot, \& Christensen, 1995). Identifying causative factors of farming system sustainability provides a framework for integrating knowledge and perspectives of the social and natural sciences into planning, policy and decision-making at farm scale. Such an interdisciplinary framework simultaneously addresses the socioeconomic and environmental guidelines of natural resource policy and agricultural management.

The current paper intends to analysis the socioeconomic determinants of sustainability in terms of ecological variables (Tillage practices, crop/land rotation, erosion, weed, disease, and pollution control methods, etc.) to create composite index of sustainability as dependent variables without investigating how these variables affect the sustainability.

Many factors are supposed to intermediate the effects of socioeconomic determinants on sustainability of cropping system. However, few studies have tried to examine this mediating effect. Thus, although the impact of socioeconomic factors on sustainability of cropping system has 
been shown in some studies (e.g. Karami, 2000; Maghsoudi, Iravani, \& Movahed Mohammadi, 2007; Amani \& Cizari, 2006), little is known about the mechanisms of this relationship to work out path analysis. Regarding the little knowledge on factors affecting sustainability at farm scale, this paper attempts to use path analysis method for identifying these factors using data from Golestan Province as the greatest producer of wheat in Iran.

A major purpose of this paper is to examine the socioeconomic factors affecting sustainability of wheat cropping system. Another purpose is to measure the level of sustainability by constructing composite index. The paper is organized as follows. In section 2, we focus on the literature to review related variables, factors, and components contributed to sustainability of cropping system to develop and propose an analytical model in which several factors mediate the relationship between level of sustainability and its socioeconomic determinants. Section 3 discusses the material and methods employed in this empirical analysis. Then, we test the hypothesized model by using path analysis in Section 4. Section 5 discusses the results and some recommendation are made for future research.

\section{Literature Review}

Fundamental attempts to assess sustainability of wheat cropping system in Iran were based on collecting diverse indicators for specific attributes of ecological sustainability and weighing each indicator according to its expected contribution (Karami, 2000). An Agricultural Sustainability Index (ASI) was defined by taking sum of the average production per hectare, crop rotation, use of organic and animal fertilizers, use of green fertilizers, use of crop remain and straw, water resource change trend, soil fertilizer and using conservation plough exploited as positive factors of sustainability. On the other hand, use of pesticides, nitrate fertilizer, and phosphate fertilizer exploited are counted as negative causative factors of sustainability. The following analytical framework addresses the factors contributing to sustainability of wheat cropping system. The framework (Figure 1) relies on the concept of causality and allows a systematic identification of components to define variables and indicators related to farming system sustainability.

The frameworks developed by other scholars in Iran were based on this analytical framework and used similar variables and indicators adopted in the agricultural sustainability literature. "Technical knowledge" has been found to increase the sustainability level of farming system in both cropping and livestock farming systems in many studies (Nikdokht, Karami, \& Ahmadvand, 2007; Sadighi \& Rousta, 2003; Maghsoudi et al., 2007). Farmers who have high technical knowledge significantly use farm practices related to sustainability such as crop rotation, land rotation, using green and organic manures, IPM, rotational grazing, tillage for seed bed preparation, and cultivation for weed control. They simultaneously lower use of petroleum-based products, commercial fertilizers, pesticides, hormones or growth stimulators, and antibiotics (Hosseini, Kalantari, Naderi Mahiyi, 2005).

Also significant direct relationship between "technical knowledge" and "access to information channels" and "level of farmer education" has been confirmed in some former studies (Sadighi \& Rousta, 2003; Maghsoudi et al., 2007). Furthermore, Maghsoudi et al. (2007) found that "perceived support facilitations", "social participation", "satisfaction of farming job", and "attitude toward sustainability" were positively and "farmer age" was negatively associated with sustainability of potato cultivation. Another factors that often reported to have positively related with sustainability of farming system are "farm income" (Amani \& Chizari, 2006; Iravani \& Darban-Astaneh, 2004), "agricultural extension-education services” (Sadighi \& Rousta, 2003; Maghsoudi et

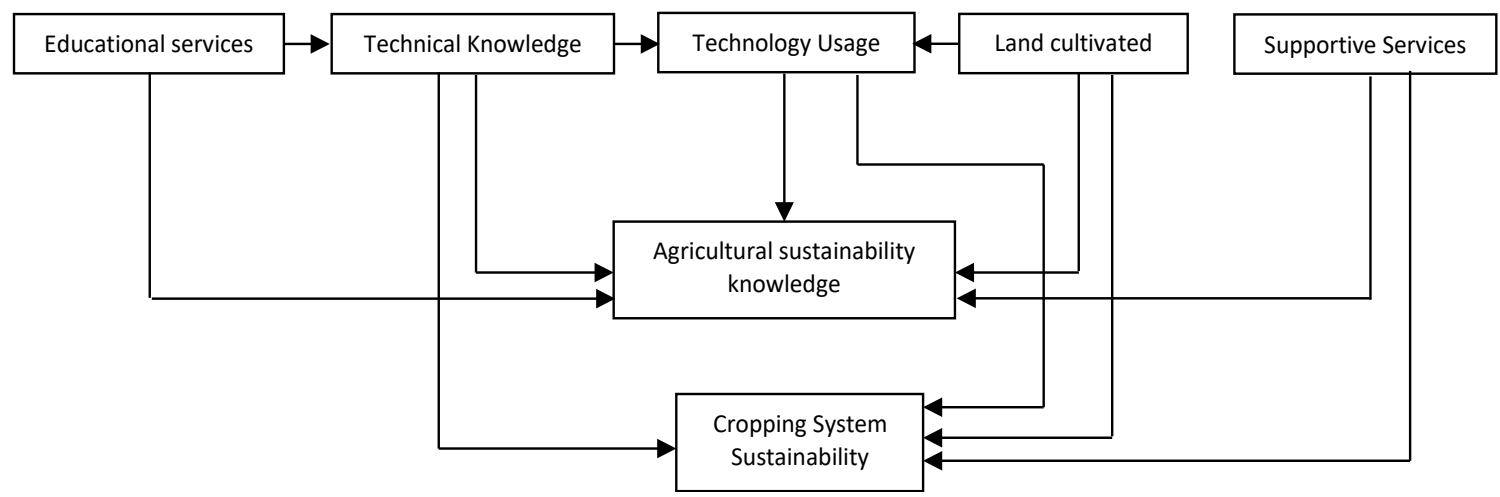

Figure 1. Analytical framework of causative factors of cropping system (Adapted from Karami, 2000) 
al., 2007), "social altitudes” (Maghsoudi et al., 2007), and "productivity" (Iravani \& Darban-Astaneh, 2004).

Various studies have found "land fragmentation" indicators such as number of land plots and plot size have negative effects on sustainability at cropping system scale (Amani \& Chizari, 2006). In addition, similar research by Hayati (1995) showed no significant correlation between variables of "age", "education", "progress motive", and "farm distance to agricultural services center", with sustainability level of wheat cropping system. The issue of sustainability technology usage by farmers has generally focused either on the technology adoption processes at the farm level or identifying characteristics associated with usage of individual technologies (e.g. IPM usage, soil conservation practices, crop/land rota- tion etc.). These characteristics have been used to measure level of technology usage among farmers. Also in other research studies, extensive consumption of chemical manure and pesticides, permanent cultivation without crop rotation, not utilizing organic and green manure and crop remain, and ignoring conservative plough were reported as the main causative factors associated with unsustainability of cropping system (Rezaei Moghaddam \& Karami, 1998).

Many previous studies, except Karami (2000), have examined the direct effects of socioeconomic determinants on sustainability of farming system, without using the meditating variables. This research tries to extend the previous studies by investigating the path between sustainability of wheat cropping system as a dependent

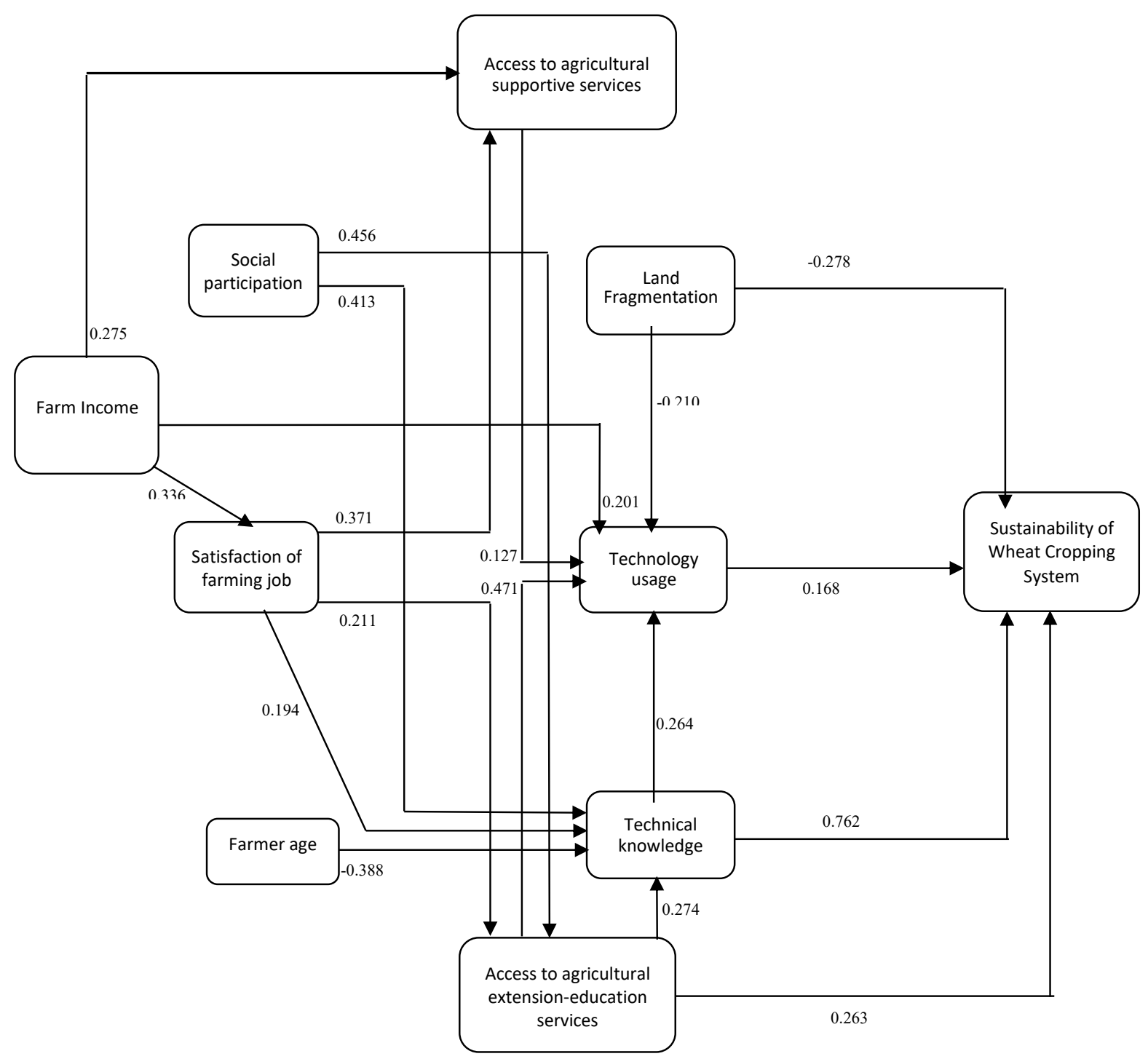

Figure 2. Theoretical framework 
variable and the socioeconomic factors as independent variables. According to the literature, 9 factors which might affect the sustainability of cropping systems were identified. They were as follows: "technical knowledge", "technology usage", "land fragmentation", "attitude toward sustainability", "farm income", "access to agricultural extension and education services", "access to agricultural supportive services", "satisfaction of farming job", and "social participation in rural affairs".

The relationship between the first five factors and sustainability of cropping system is straightforward. However, an indirect path exists between "farm income", "satisfaction of farming job", and "social participation" with sustainability by mediating through first five factors. All of these variables are hypothesized to impact the sustainability of wheat cropping system (Figure 2).

\section{Methodology}

Sample selection and survey

For the purpose of this study, the heads of the selected households in the study area were interviewed, using a structured and semi-structured questionnaire in 2016. To prepare the study questionnaire, an informal survey was

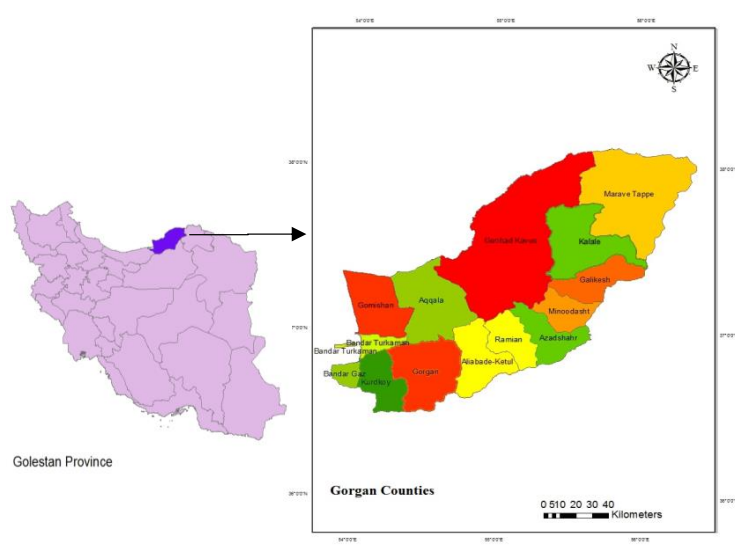

Figure 3. 13 counties in Golestan province

JSRD

conducted by holding interviews with key informants, including 10 farmers, university faculty members, government officials, nongovernment organizations, and other research agencies. A random two-stage sampling technique was used to select the sample of farmers. In the first stage, 5 counties were randomly selected among 13 counties in Golestan Province (Figure 3). Then 6 villages were selected among these counties and finally a complete list of 30 villages was available. In the second stage, farmers in the 30 sampled villages were listed.

Table 1. Indicators used to construct composite index of sustainability

\begin{tabular}{|c|c|}
\hline & Indicators \\
\hline 1 & Amount of organic manures used $\mathrm{kg} / \mathrm{ha}(+)$ \\
\hline 2 & Amount of macro manures used kg/ha (+) \\
\hline 3 & Amount of animal manures used $\mathrm{kg} / \mathrm{ha}(+)$ \\
\hline 4 & Amount of nitrate fertilizers used kg/ha (-) \\
\hline 5 & Amount of phosphor fertilizers used kg/ha (-) \\
\hline 6 & Amount of chemical herbicides L/ha (-) \\
\hline 7 & Amount of chemical pesticides L/ha (-) \\
\hline 8 & Amount of chemical fungicides $L /$ ha (-) \\
\hline 9 & $\%$ of land cultivated under crop rotation system (+) \\
\hline 10 & $\%$ of land cultivated under land rotation system (+) \\
\hline 11 & Burning of crop residues per ha (-) \\
\hline 12 & Number of crop planted annually (+) \\
\hline 13 & $\%$ of converting arable lands (-) \\
\hline
\end{tabular}

$(+)$ and (-) are indicators with positive and negative effect on sustainability. 
The survey covered 236 farmers randomly selected in proportion to the number of farmers in each village. Two farmers were eliminated from the analysis because of missing information in their questionnaires. The type of data collected was concerned variables associated with conceptual framework such as using sustainable farming practice methods (crop/land rotation, organic, green and animal fertilizers, crop remain and straw, conservation plough); farmer and village factors such as age, education, income, access and contact with service, research and extension agencies, and farmers' attitude toward sustainability; farm characteristics such as land fragmentation, land cultivated; and social and institutional factors such as satisfaction farming job, preferences with regard to sustainability and social participation.

\section{Collecting sustainability measures}

Many studies propose to assess sustainability by the means of collecting a set of indicators (Sydorovych \& Wossink, 2008). In this paper, sustainability level of wheat cropping system as the dependent variable was assessed by the construct of Sustainability Composite Index (SCI). SCI comprises 13 indicators that measures sustainability level in a wheat cropping system (Table 1).

In the present study, principal components method was used to derive composite index. In order to develop the composite index, dividing by mean method was used to remove the scale biases. Also to change the negative indica-

Table 2. Items and scale reliability

\begin{tabular}{cc}
\hline Scale & Reliability (Cronbach's $\boldsymbol{\alpha})$ \\
\hline Technical knowledge & 0.921 \\
\hline Accessibility on agricultural extension and education services & 0.945 \\
Accessibility on agricultural supportive services & 0.844 \\
Satisfaction of farming job & 0.822 \\
Social participation in rural affairs & 0.765 \\
Technology usage & 0.874 \\
\hline
\end{tabular}

- JSRD

Table 3. Descriptive statistics of key variables

\begin{tabular}{ccccc}
\hline Variables & Mean & SD & Minimum & Maximum \\
\hline Land fragmentation (number of plots under wheat cultivated) & 9.80 & 7.33 & 1 & 50 \\
Average plot size (ha) & 1.14 & 12.35 & 0.20 & 80 \\
\hline Family size (number of people in a family) & 6.54 & 2.89 & 2 & 94.20 \\
Labor force of household (\%) & 70.92 & 26.92 & 8.42 & 23.69 \\
Share of off-farm income (\%) & 9.10 & 5.45 & 1.63 & 40000 \\
\hline Average annual income from agriculture (1000000 IRR) & 12294.70 & 13408.20 & 2800 & 61 \\
Farming experience (y) & 26 & 15.01 & 1 & 75 \\
Age of farmers & 46.85 & 12.55 & 22 & 35 \\
Wheat cultivated land (ha) & 6.23 & 6.98 & 2 & 100 \\
\hline Total land area under ownership (ha) & 11.33 & 8.12 & 2 & 7.50 \\
\hline Average wheat yield (ton/ha) & 4.84 & 1.25 & 1.5 & \\
\hline
\end{tabular}


Table 4. The level of sustainability of wheat cropping system

\begin{tabular}{cccc}
\hline Level of Sustainability & No. & $\%$ & Cumulative \% \\
\hline Very low sustainability & 22 & 9.40 & 6.40 \\
\hline Low sustainability & 138 & 58.97 & 89.32 \\
Medium & 49 & 20.94 & 98.72 \\
\hline High sustainability & 22 & 9.40 & 100.00 \\
\hline Very high sustainability & 3 & 1.28 & \\
\hline
\end{tabular}

tors to positive, converting value of the indicators done for each indicator with negative value (Hosseini et al., 2005).

Thus the measure adopted for the removing scale bias and calculating composite index is follows:

$$
S C I=\sum_{i=1}^{n} \frac{x_{\ddot{y}}}{\bar{x}} \times W_{1 i}
$$

, where SCI is Sustainability Composite Index for wheat cropping systems, $x i j$ is the $\mathrm{i}^{\text {th }}$ indicator of the $\mathrm{j}$ th farmer, $\bar{x}_{i}$ is the mean of the $\mathrm{X}_{\mathrm{i}}$ indicator, and wij is the factor loading of the first principal component vector relating to $\mathrm{i}^{\text {th }}$ indicator. Moreover, SCI was used for the measurement of farming system sustainability. It was analyzed by cluster analysis (Hierarchical model and Centroid method) to categories level of sustainability which was derived from dendrogram.

\section{Study instrument}

A preliminary set of questions about items and scales related to independent variables was developed and pretested on 50 farmers. Scales were then developed for the issues of primary concern; "technical knowledge", "access to agricultural extension and education services", "access to agricultural supportive services", "satisfaction of farming job, and social participation in rural affairs" and "technology usage". The scales included 5-point items (Likert-type scale). The final developed scales reliability during this stage are shown in Table 2. The reliability values for these scales ranges from 0.765 to 0.945 , which are acceptable. Also the total score was used in this study and calculated by adding the subscales.

\section{Data analysis}

Path analysis, a particular form of multivariate analysis, was used to trace the impact of independent variables on the sustainability of wheat cropping system as dependent variable. It acknowledges to test a causal pathway of variables by allowing variables to act as both independent and dependent (Kline, 1998). The path analysis estimates the magnitude of the relationship between variables, and tests the proposed model, too. Path coefficients were obtained using step-wise multiple regression analysis by including the focal variable as the criterion variable, and those which are expected to directly influence it as predictors. After the initial analysis, the model is "trimmed" to eliminate variables with little impact, retaining only significant variables. In this initial analysis, SPSS was used to conduct a series of 9 regression analyses.

\section{Findings}

\section{Descriptive analysis}

Some key characteristics of farmers' households are presented in Table 3. The number of plots cultivated by a household as land fragmentation measures ranges from 1 to 50 . The average is 9.80 plots per household while the average plot size varies from 0.20 to 80 ha, with an average of 1.14 ha. The average family size equals 6.54 people, and about $70.92 \%$ of the household members belonged to the farming labor force. Considering the share of off-farm income of the households in the sample (mean value: $9.10 \%$ ), households that are heavily involved in offfarm employment were not included in the sample. However, household average net annual income varies from 28 to 400 million Rials ${ }^{1}$ with an average of 122 million Rials. Farmer's experience in agricultural activities were ranged from 1 to 61 years (26 years, on average) while the average age of them was 46.85 years and ranged between 22 and 75 years. According to the results, total land area under household ownership is 16.29 ha, that 6.23 ha of is under wheat cultivation. As shown in Table 3, the average wheat yield is 4.84 ton/ha ranging from 1.5 to 7.50 .

1. Each dollar was 35000 Rials in 2016 
Table 5. Path analysis results

\begin{tabular}{|c|c|c|c|c|}
\hline \multirow{2}{*}{ Criterion } & \multirow{2}{*}{ Predictor } & \multicolumn{2}{|c|}{ Regression Coefficient } & \multirow{2}{*}{$\mathbf{R}^{2}$} \\
\hline & & Unstandardized & Standardized & \\
\hline \multirow{6}{*}{$\begin{array}{l}\text { Sustainability of wheat cropping } \\
\text { system }\end{array}$} & Supportive services & 0.102 & 0.014 & \multirow{6}{*}{$0.525^{* * * *}$} \\
\hline & Land fragmentation & $-6.859 * * *$ & -0.257 & \\
\hline & Technology usage & $2.909 * * *$ & 0.176 & \\
\hline & Attitude toward sustainability & 1.757 & 0.051 & \\
\hline & Technical knowledge & $3.280 * * *$ & 0.779 & \\
\hline & Extension-education services & $1.764^{* *}$ & 0.226 & \\
\hline \multirow{3}{*}{ Supportive services } & Satisfaction of farming job & $0.564^{* *}$ & 0.388 & \multirow{3}{*}{$0.251 * * *$} \\
\hline & Social participation & 0.071 & 0.072 & \\
\hline & Farm income & $0.267^{* * * *}$ & 0.266 & \\
\hline Land fragmentation & Farm income & -0.223 & -0.159 & 0.011 \\
\hline \multirow{7}{*}{ Technology usage } & Land fragmentation & $-0.213^{* * *}$ & -0.215 & \multirow{7}{*}{$0.398^{* * * *}$} \\
\hline & Farm income & $0.042 * * *$ & 0.183 & \\
\hline & Supportive services & $0.117^{*}$ & 0.129 & \\
\hline & & & & \\
\hline & Extension-education services & $0.459 * * *$ & 0.467 & \\
\hline & Technical knowledge & $0.264^{* * * *}$ & 0.266 & \\
\hline & Satisfaction of farming job & 0.044 & 0.045 & \\
\hline \multirow{3}{*}{ Attitude toward sustainability } & Satisfaction of farming job & 0.179 & 0.134 & \multirow{3}{*}{0.024} \\
\hline & & & & \\
\hline & Farmer age & -0.144 & -0.098 & \\
\hline \multirow{5}{*}{ Technical knowledge } & Social participation & $0.851^{* * *}$ & 0.413 & \multirow{5}{*}{$0.413^{* * * *}$} \\
\hline & Satisfaction of farming job & $0.373^{* *}$ & 0.198 & \\
\hline & & & & \\
\hline & Extension-education services & $0.558^{* * *}$ & 0.274 & \\
\hline & Farmer age & $-0.186^{*}$ & -0.388 & \\
\hline \multirow{5}{*}{ Extension-education services } & Supportive services & 0.083 & 0.170 & \multirow{5}{*}{$0.319 * *$} \\
\hline & Farm income & 0.048 & 0.092 & \\
\hline & & & & \\
\hline & Social participation & $0.243^{* * *}$ & 0.458 & \\
\hline & Satisfaction of farming job & $0.112^{* * *}$ & 0.211 & \\
\hline Social participation & Farm income & 0.057 & 0.062 & 0.004 \\
\hline Satisfaction of farming job & Farm income & $0.331^{* *}$ & 0.336 & $0.113^{* *}$ \\
\hline
\end{tabular}


Table 6. Trimmed path analysis results

\begin{tabular}{|c|c|c|c|c|}
\hline \multirow{2}{*}{ Criterion } & \multirow{2}{*}{ Predictor } & \multicolumn{2}{|c|}{ Regression Coefficient } & \multirow{2}{*}{$\mathbf{R}^{2}$} \\
\hline & & Unstandardized & Standardized & \\
\hline \multirow{4}{*}{$\begin{array}{l}\text { Sustainability of wheat } \\
\text { cropping system }\end{array}$} & Land fragmentation & $-7.486^{\star \star \star}$ & -0.278 & \multirow{4}{*}{$0.499^{\star \star \star}$} \\
\hline & Technology usage & $2.783^{\star \star \star}$ & 0.165 & \\
\hline & Technical knowledge & $3.262^{\star \star \star}$ & 0.762 & \\
\hline & Extension-education services & $2.072^{\star \star \star}$ & 0.263 & \\
\hline \multirow{3}{*}{ Supportive services } & Satisfaction of farming job & $0.540^{\star \star \star}$ & 0.371 & \multirow{3}{*}{$0.246^{\star \star \star}$} \\
\hline & & & & \\
\hline & Farm income & $0.277^{\star \star \star}$ & 0.275 & \\
\hline \multirow{5}{*}{ Technology usage } & Land fragmentation & $-0.209^{\star \star \star}$ & -0.210 & \multirow{5}{*}{$0.396^{\star \star \star}$} \\
\hline & Farm income & $0.046^{\star \star}$ & 0.201 & \\
\hline & Supportive services & $0.116^{\star}$ & 0.127 & \\
\hline & Extension-education services & $0.463^{\star \star \star}$ & 0.471 & \\
\hline & Technical knowledge & $0.262^{\star \star}$ & 0.264 & \\
\hline \multirow{5}{*}{ Technical knowledge } & Social participation & $0.851^{\star \star \star}$ & 0.413 & \multirow{5}{*}{$0.413^{\star \star \star}$} \\
\hline & Satisfaction of farming job & $0.373^{\star \star}$ & 0.198 & \\
\hline & & & & \\
\hline & Extension-education services & $0.558^{\star \star \star}$ & 0.274 & \\
\hline & Farmer age & $-0.186^{\star}$ & -0.388 & \\
\hline \multirow{2}{*}{$\begin{array}{l}\text { Extension-education } \\
\text { services }\end{array}$} & Social participation & $0.242^{\star \star \star}$ & 0.456 & \multirow{2}{*}{$0.310^{\star \star \star}$} \\
\hline & Satisfaction of farming job & $0.112^{\star \star}$ & 0.211 & \\
\hline Satisfaction of farming job & Farm Income & $0.331^{\star \star}$ & 0.336 & $0.113^{\star \star}$ \\
\hline
\end{tabular}

\section{Level of sustainability}

SCI was considered as a final variable and entered in cluster analysis. The results of cluster analysis were classified in 5 categories (Table 4). According to the findings, dominant form of wheat cropping system was unsustainable as $9.40 \%$ of the farmers were deified in very low sustainability category and $58.97 \%$ belonged to low sustainability category based on total composite index. While $9.40 \%$ of farmers were in the high sustainability category and $1.28 \%$ in the very high sustainability category.

\section{Path analysis}

A path analysis was conducted on the model proposed in the previous section. As the qualitative variables of this model were measured through various items in the form of Likert-type scale; by adding up these items, a quantitative set of data for each variable was obtained and the path analysis was calculated. The results are shown in Table 5, illustrating each criterion variable with their predictor variables, as well as their significance. The model was then trimmed with all non-significant variables and then re-run with the variables at significance $<0.05$. These results are presented in Table 5 .

According to Figure 4, both "access to agricultural supportive services" and "attitude toward sustainability", as defined in the literature review, did not have significant and direct impact on the sustainability of wheat cropping system in the path analysis. The factors found to impact directly were "land fragmentation", "technology usage", technical knowledge", and "access to extension-education services". The standardized coefficients for "land fragmentation", "technology usage", "technical knowledge", and "access to extension-education services" in 
Table 7. Direct and indirect impacts of the independent variables on sustainability of wheat cropping

\begin{tabular}{|cccc}
\hline Variable & Direct Impact & Indirect Impact & Total Impact \\
\hline Land fragmentation & -0.278 & 0.035 & -0.313 \\
\hline Technology usage & 0.165 & - & 0.165 \\
\hline Technical knowledge & 0.762 & 0.044 & 0.806 \\
\hline Extension-education services & 0.263 & 0.298 & 0.561 \\
\hline Satisfaction of farming job & - & 0.321 & 0.321 \\
\hline Farm income & - & 0.020 & 0.020 \\
\hline Supportive services & - & 0.021 & 0.021 \\
\hline Social participation & - & 0.047 & 0.047 \\
\hline Farmer age & - & -0.398 & -0.398 \\
\hline
\end{tabular}

this equation were $-0.278,0.165,0.762$, and 0.263 , respectively (Table 6).

The total direct and indirect effects of these four variables were $-0.313,0.165,0.806$ and 0.561 , respectively (Table 7). $\mathrm{R}^{2}$ for the equation was 0.499 , indicating that these four factors explained almost half of the variance in the dependent variable. The impact of land fragmentation over the sustainability of wheat cropping system and farmer age is negative (indirect impact is 0.398) whereas the rest of variables effects on the sustainability of wheat cropping system are positive. Nevertheless, "access to agricultural supportive services" did not have a direct influence on sustainability of wheat cropping system, but it acts indirectly (indirect impact $=0.021$ ) through "technology usage".

On the whole, the indirect effects of the "satisfaction of farming job" variable is 0.321 whereas mediated by "access to agricultural supportive services" (0.371), "technical knowledge" (0.198) and "access to agricultural extension-education services" (0.211). Also "farm income", "supportive services", and "social participation" have indirect effects on the sustainability of wheat cropping system $(0.020,0.021$, and 0.047 , respectively). "Technical knowledge" has the largest total impact (0.806) on the sustainability of wheat cropping system, followed by "extension-education services" (0.561), "farmer age" (-0.398), "satisfaction of farming job" (0.321), "land fragmentation" (-0.313), "technology usage” (0.165), "social participation" (0.047), "supportive services" (0.021), and "farm income" (0.020). Only "at- titude toward sustainability" did not have statistically significant direct or indirect effect on sustainability of wheat cropping system.

\section{Discussion}

The traditional or conventional agricultural system extends all over Iran. Exploitation of production resources based on this type of agriculture faces great challenge occasioned by the high level of depletion, environmental degradation thereby threatening the sustainability of agriculture itself as well as the health of people consuming its products. Some efforts have been made in Iran during the past decade or more to promote farming system in the interests of sustainability and long-term conservation of the agricultural production resources. In this regard, socioeconomic factors play key role and a pioneering endeavor aimed at making agriculture environmentally sound, economically viable, and socially acceptable. Hence there is an urgent need to identify and determine the socioeconomic factors associated with sustainability of farming system. This study assessed the impact of socioeconomic factors on the sustainability of wheat cropping system and measuring the level of sustainability committing ecological indicators as assessed through an elevated composite index. This study enriches our understanding on farmers and farming system characteristics that can enhance or retard sustainability practice in agricultural farming system.

Data from a survey of 234 farmers in Golestan Province were used to determine the factors associated with 


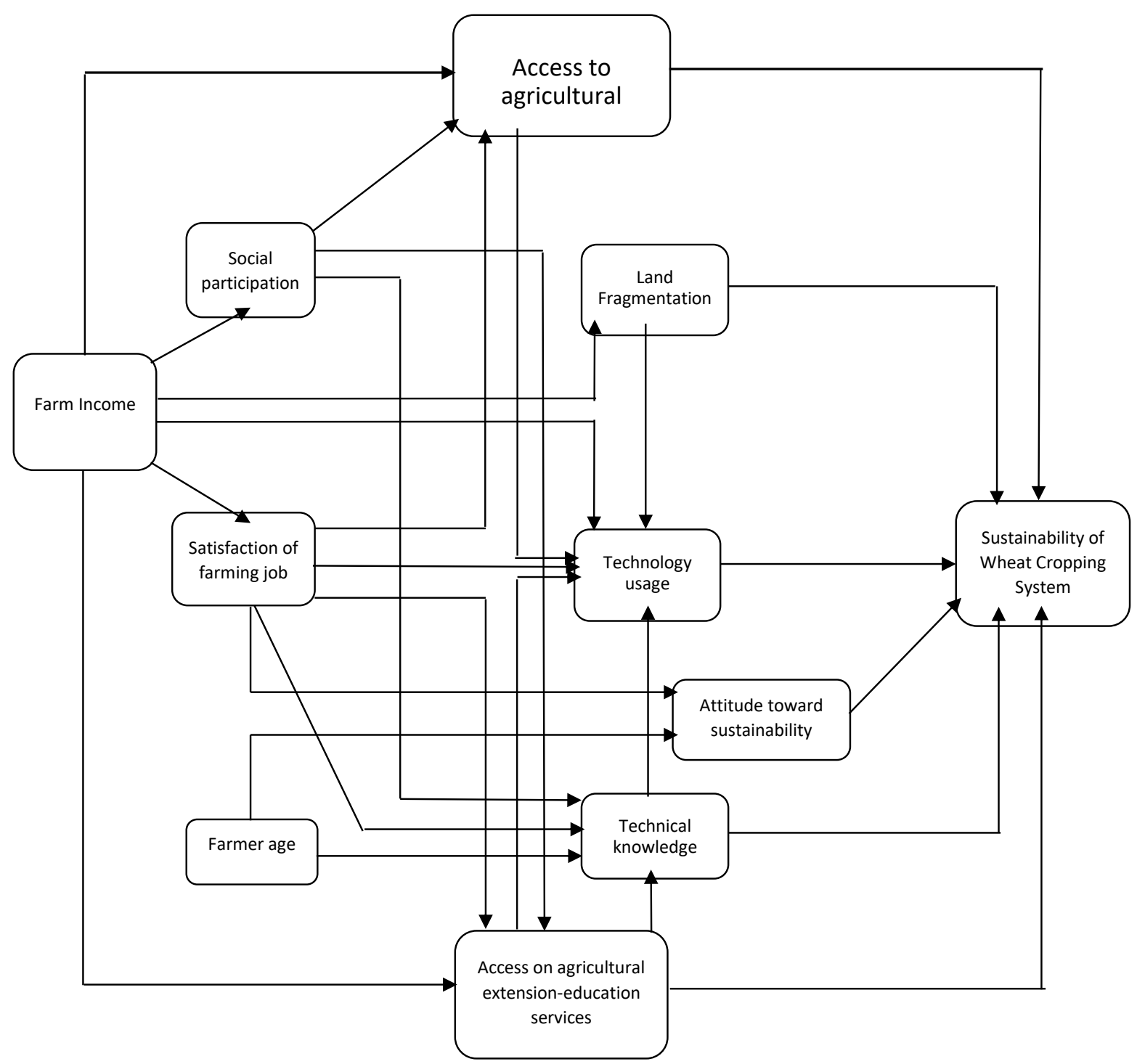

Figure 4. Trimmed (eliminate variables with little impact) results of path analysis

the sustainability. According to the study results, a main characteristic of the wheat cropping system was its unsustainable situation. Then a path analysis was conducted to test the path of the variables. The trimmed path analysis model found the direct and significant impact of "land fragmentation", "technology usage", "technical knowledge", and "access to extension-education services" on the sustainability of wheat cropping system. This finding is similar to the results of previous research which found that the "usage of modern technology" (Karmi, 2000), "technical knowledge" (Hayati, 1995; Karmi, 2000; Sadighi and Rousta, 2003) and "number of farmland plot" (Amani and Cizari, 2006) affect the sustainability of farming system. Maghsoudi et al. (2007), however, did not enter this regression analysis, and reported that age, cultivated land, and membership in agricultural cooperative had significant correlation with sustainability.
The fact that the majority of the sample consisted of low-income, livelihood farmers with small and fragmented plots in which cultivation is carried on to non-geometric small-scale plots may help explain the relatively high impact of "land fragmentation" and "technology usage". These farmers have limited resources to use farm machinery and new cultivation methods such as chemical fertilizers, pesticides, and herbicides to optimize their productions. Therefore, application of suitable and small technology and consolidated farmland, aimed at increasing yield, efficiency and reducing production costs, have a direct relationship with sustainability and optimum application of agricultural production resources. Also the low productivity of small farms constrains sustainable crop production at regional and national level. Moreover, agricultural extension-education services will improve sustainability. 


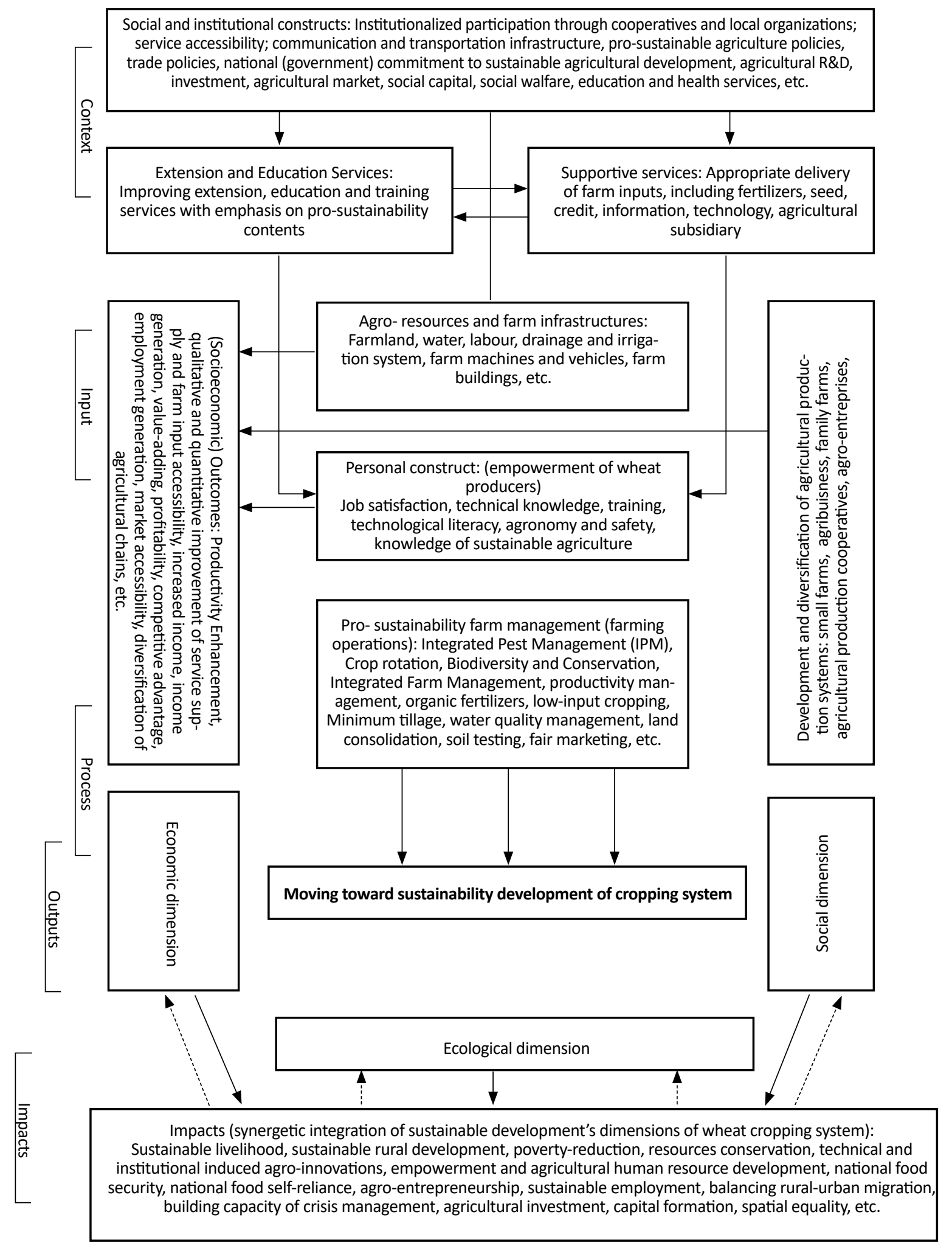

Figure 5. A suggested framework for enhancing sustainability of wheat cropping system 
Technical knowledge, skills and ideas also develop farmers' capacity in facing the challenges of sustainable agriculture and in adopting and using new technologies for exploiting agricultural natural resources. Same results were reported by Sadighi and Rousta (2003) in study conducted on corn cultivation system by low-income farmers. They found that farmers who had more on-farm visit by agricultural extension agents showed significantly more sustainable farming compared to farmers who neglected their on-farm visit. As hypothesized, "technical knowledge" has a significant influence on sustainability of cropping system.

In this study, total impact of this factor is the largest and strongly supported by previous research (Rezaei Moghaddam, \& Karami 1998; Karami, 2000). “Technical knowledge" includes a large number of skills related to sustainable farming practice such as type of crop rotation and fallow, multiple cropping, relay cropping, use of leftover, conservative tillage, integrated farm management, and integrated pest management. Therefore, it is natural to consider high knowledge and skills of sustainable farming practices as the first important factor in sustainability of wheat cropping system. In addition, age was negatively associated with the level of sustainability through technical knowledge, because younger farmers are more likely to adopt and use new technologies related to sustainability and/or are more likely to be early adopters.

Obviously, the key to sustainable and sound agricultural growth is technology, hence the question is: what kind of 'technically knowledge' is required for farmers to promote sustainable farming practices? Rezaei-Moghaddam et al. (2005) employed two opposing polar conceptual paths; Ecological Modernization (EM) and De-Modernization (DM) theories to explain the sustainability of agricultural development in Iran. They remarked that, based on DM theory, modern technology is the cause of all environmental problems and the only practical and possible strategy for agricultural development is a radical goodbye to modern and scientific technologies by transforming conventional agriculture to traditional farming systems based on indigenous knowledge and technology and social organization. On the other hand, EM-based agricultural development policies should be based on the application of eco-modern (environmental) technologies in different stages of production.

The general direction of development is symbolized by the shift from the remedial strategy involving endof-pipe technology to preventive strategies involving clean-up technologies based on the precautionary principle. Therefore, it is not easy to answer the question of what sort of 'technical knowledge' farmers need to perform effectively. If the current argument be accepted we should first choose among competing paths to sustainable agriculture and then select the appropriate sort of 'technical knowledge' needed for effective sustainable farming practices accordingly.

Also human capital characteristics such as farmers' age and attitude toward sustainability were found to be insignificant determinants of the sustainability. These findings corroborated closely with the findings of Hayati (1995) in his attitudinal study of wheat producers in Fars Province. On the other hand, age and attitude were related to sustainability orientation. In view of this fact, younger farmers seem to be attitudinally more suited for sustainability-oriented programs. Further findings by Amani and Cizari (2006) and Maghsoudi et al. (2007) supported this view. However, the "access to agricultural supportive services", "social participation", "satisfaction of farming job", and "farm income" had an indirect impact over the sustainability through four previous variables. Some studies have found that these factors directly affect sustainably level of farming system in Iran (Iravani \& Darban-Astaneh, 2004; Hayati, 1995). These results would indicate that sustainability in farm scale is not enough because the out farm compensatory factors influence the farmer's efforts at farm scale. Although supportive, extension, and education services are provided by Ministry of Agriculture Jihad (MAJ), the main decision is how to provide these services according to needs and conditions at farm scale. Therefore, farmers will ultimately bear the responsibility for implementing the policies and guidelines necessary for sustainable agriculture.

In conclusion, to promote sustainability of farming system in Iran, all subsystems related to sustainable agricultural activity should be considered. According to results and experts' views, all processes that can provide sustainable agriculture condition are presented in Figure 5. In the context phase, social and institutional constructs should be provided to inform farmers of how to use agro-resources and farm infrastructures, extension and education services, and supportive services as inputs for crop production. At the same time, some subsystems such as development and diversification of agricultural production systems, personal construct in process and output phase interact the whole system and produce socioeconomic outcome. Results of these phases are moving toward sustainable development of cropping system. The cycle can be completed by impact phase in which feedback for three main dimensions of sustainability are created. These phases in turn improve preparedness to promote sustainability and act friendly with the natural 
resources at farm scale, particularly with the help of stakeholders. By strengthening the links among these subsystems, related stakeholders, including policymakers, researchers, experts, and farmers, the farmers' constraints and priorities would be better understood and information transfer would be more effective. Linkages could be strengthened through joint researchextension meetings and workshops, field visits, farmer training and on-farm research.

In case of Golestan, farmers should be advised about sustainable agricultural practices, quality, quantity and standards of using production inputs, especially chemical fertilizers, herbicides and pesticide, export demand and expectations, as well as the farmer organization and union and its function. At same time, it is very important that farmers are provided with financial, credit and complementary services and support in transition to sustainable agriculture and given guarantees regarding marketing of their products.

\section{Acknowledgements}

This research did not receive any specific grant from funding agencies in the public, commercial, or not-forprofit sectors.

\section{Conflict of Interest}

The authors declared no conflicts of interest.

\section{References}

Alonge, A. J., \& Martin, R. A. (1995). Assessment of the adoption of sustainable agriculture practices: Implications for agricultural education. Journal of Agricultural Education, 36(3), 34-42. doi: $10.5032 /$ jae.1995.03034

Amani, A. R., Cizari, M. (2006). [Sustainability analysis of wheat cropping system (Case study in Khuzestan Province) (Persian)]. Iranian Journal of Agriculture Science, 37-2(2), 257-66.

Carpenter, S. R., Mooney, H. A., Agard, J., Capistrano, D., DeFries, R. S., Diaz, S., et al. (2009). Science for managing ecosystem services: Beyond the millennium ecosystem assessment. Proceedings of the National Academy of Sciences, 106(5), 1305-12. doi: $10.1073 /$ pnas. 0808772106

Charles, F., \& Youngberg, G. (1990). Sustainable agriculture: An overview. In C. A. Francis., C. B. Flora, \& L. D. King (Eds.) Sustainable agriculture in temperate zones (pp. 1-23). New York: John Wiley \& Sons.
Clark, W. C., \& Dickson, N. M. (2003). Sustainability science: The emerging research program. National Academy of Sciences, 100(14), 8059-61. doi: 10.1073/pnas.1231333100

Dalsgaard, J. P. T., Lightfoot, C., \& Christensen, V. (1995). Towards quantification of ecological sustainability in farming systems analysis. Ecological Engineering, 4(3), 181-9. doi: 10.1016/0925-8574(94)00057-c

De Luca, A. I., Iofrida, N., Leskinen, P., Stillitano, T., Falcone, G. Strano, A., \& Gulisano, G. (2017). Life cycle tools combined with multi-criteria and participatory methods for agricultural sustainability: Insights from a systematic and critical review. Science of The Total Environment, 595, 352-70. doi: 10.1016/j. scitotenv.2017.03.284

Edwards, C. A., Madden, R., Miller, P., RH House, G., Madden, P. D., \& Madden, P. (1990). Sustainable agricultural systems (No GTZ-149). Ankeny: Soil and Water Conservation Society.

Francis, C., Lieblein, G., Gliessman, S., Breland, T. A., Creamer N., Harwood, R., et al. (2003). Agroecology: The ecology of food systems. Journal of Sustainable Agriculture, 22(3), 99-118. doi: 10.1300/j064v22n03_10

Hansen, J. W., \& Jones, J. W. (1996). A systems framework for characterizing farm sustainability. Agricultural Systems, 51(2), 185-201. doi: 10.1016/0308-521x(95)00036-5

Harwood, R. (1993). A look back at USDA's report and recommendations on organic farming. American Journal of Alternative Agriculture, 8(4), 150-4. doi: 10.1017/s0889189300005270

Hayati, D. (1995). Influential characteristics of socio-economic, farming and production on technical knowledge and sustainable technical knowledge among wheat producers in Fars province (Persian)] [MSc. thesis]. Shiraz: Shiraz University.

Hosseini, S. M., Kalantari, Kh., Naderi Mahiyi, K. (2005). [A study of ecological sustainability in farming systems of Saleh Abad District, Hamadan (Persian)]. Iranian Journal of Agriculture Science, 38-2(1), 91-8.

Ikerd, J. (1996). Sustainable Agriculture: Do We Really Need to Define It? Paper presented at The Michigan Agriculture MegaConference; Lansing, Michigan, 12 January 1996.

Ikerd, J., Devino, G., \& Traiyongwanich, S. (1996). Evaluating the sustainability of alternative farming systems: A case study. American Journal of Alternative Agriculture, 11(1), 25-9. doi: 10.1017 /s088918930000669x

Iravani, H., \& Darban Astaneh, A. R. (2004). [Measurement analysis and exploitation of the sustainability of farming systems (Case study: Wheat production, Tehran Province) (Persian)]. Iranian Journal of Agriculture Science, 35(1), 25-39.

Karami, E. (2000). [Socio-economic factors contributing to sustainable agricultural knowledge and farm sustainability of wheat producers (Persian)]. Tehran: Ministry of Agriculture.

Kline, R. B. (1998). Principle and practice of structural modeling. New York: Guilford Press.

Levin, S. A., \& Clark, W. C. (2010). Toward a science of sustainability: Report from toward a science of sustainability conference; Airlie Center Warrenton, Virginia (No. 196). Cambridge: Center for International Development at Harvard University.

Madden, J. P., \& Chaplowe, S. G. (1995). Introduction and overview. In J. Patrick Madden (Ed), For All Generations: Making 
World Agriculture More Sustainable (pp. 3-37). Glendale: OM Publishing.

Maghsoudi, T., Iravani, H., \& Movahed Mohammadi, H. (2007). [Measuring and analyzing of factors affecting on the sustainability of potato cultivation system (Case study: Ferydonshahr County) (Persian)]. Journal of Village and Development, 9(6), 153-69.

Miller, T. R. (2014). Reconstructing sustainability science: Knowledge and action for a sustainable future. New York: Routledge.

Ministry of Agriculture. (2005). [Report on result, achievement and indicators of Iranian Agricultural Sector (Persian)]. Tehran: Ministry of Jihad-e Kheshavarzi.

Nikdokht, R., Karami, E., \& Ahmadvand, M. (2007). [Comparative analysis of sustainability in traditional livestock production systems: The case of animal husbandries in Firouzabad County (Persian)]. JWSS-Isfahan University of Technology, 11(41), 433-42.

Park, J., \& Seaton, R. A. F. (1996). Integrative research and sustainable agriculture. Agricultural Systems, 50(1), 81-100. doi: $10.1016 / 0308-521 x(94) 00050-2$

Pashaei Kamali, F., Borges, J. A. R., Meuwissen, M. P. M., de Boer, I. J. M., \& Oude Lansink, A. G. J. M. (2017). Sustainability assessment of agricultural systems: The validity of expert opinion and robustness of a multi-criteria analysis. Agricultural Systems, 157, 118-28. doi: 10.1016/j.agsy.2017.07.013

Rao, N. H., \& Rogers, P. P. (2006). Assessment of agricultural sustainability. Current Science, 91(4), 439-48.

Rezaei Moghaddam, K., \& Karami, E. (1998). [Agricultural extension, poverty and sustainable agriculture: Path analysis function (Persian)]. Iranian Agricultural Extension and Education Journal, 2(1), 55-72.

Rezaei Moghaddam, K., Karami, E., \& Gibson, J. (2005). Conceptualizing sustainable agriculture: Iran as an illustrative case. Journal of Sustainable Agriculture, 27(3), 25-56. doi: 10.1300/ j064v27n03_04

Roberts, W. S., \& Swinton, S. M. (1996). Economic methods for comparing alternative crop production systems: A review of the literature. American Journal of Alternative Agriculture, 11(1), 10-7. doi: $10.1017 /$ s0889189300006652

Sadighi, H., \& Rousta, K. (2003). Factors affecting sustainable agricultural knowledge of exemplary corn growers in the province of Fars, Iran. Iranian Journal of Agricultural Sciences, 34(4), 913-24.

Smolik, J. D., Dobbs, T. L., \& Rickerl, D. H. (1995). The relative sustainability of alternative, conventional, and reduced-till farming systems. American Journal of Alternative Agriculture, 10(1), 25. doi: 10.1017/s0889189300006081

Sydorovych, O., \& Wossink, A. (2008). The meaning of agricultural sustainability: Evidence from a conjoint choice survey. Agricultural Systems, 98(1), 10-20. doi: 10.1016/j. agsy.2008.03.001

Tilman, D., Cassman, K. G., Matson, P. A., Naylor, R., \& Polasky, S. (2002). Agricultural sustainability and intensive production practices. Nature, 418(6898), 671-7. doi: 10.1038/nature01014
Yunlong, C., \& Smit, B. (1994). Sustainability in agriculture: a general review. Agriculture, Ecosystems \& Environment, 49(3), 299-307. doi: 10.1016/0167-8809(94)90059-0 
